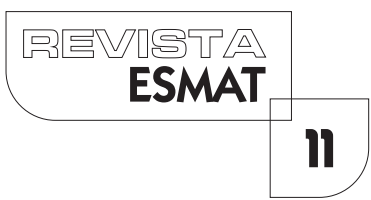

\title{
EDUCAÇÃO E JUSTIÇA RESTAURATIVA: OS DESAFIOS NA RESOLUÇÃO DE CONFLITOS NO AMBIENTE ESCOLAR
}

\author{
EDUCATION AND RESTORATIVE JUSTICE: CHALLENGES IN CONFLICT \\ RESOLUTION IN SCHOOL ENVIRONMENT
}

Paulo Fernando de Melo Martins

Professor Adjunto da Universidade Federal do Tocantins (UFT). Doutor em Educação. Docente no Programa de Pós-Graduação em Prestação Jurisdicional e Direitos Humanos Mestrado Profissional Interdisciplinar da UFT. Coordenador do Núcleo Interdisciplinar de Educação em Direitos Humanos (NIEDIH/UFT).

Julianne Freire Marques

Mestre no Programa de Pós-Graduação em Prestação Jurisdicional e Direitos Humanos Mestrado Profissional Interdisciplinar da UFT.

Halyny Mendes Guimarães

Mestranda no Programa de Pós-Graduação em Prestação Jurisdicional e Direitos Humanos Mestrado Profissional Interdisciplinar da UFT.

\section{RESUMO}

O presente artigo resulta das pesquisas desenvolvidas no Programa de Pós-Graduação em Prestação Jurisdicional e Direitos Humanos (mestrado profissional interdisciplinar) e no Núcleo Interdisciplinar de Educação em Direitos Humanos da Universidade Federal do Tocantins (UFT), entre 2013 e 20 I 5. Ainda que tenhamos avançado no processo de democratização do Brasil, sem dúvida temos a consciência de estarmos longe de uma sociedade justa e um Estado Democrático que tenha os interesses do povo na centralidade das suas ações. Para o tratamento adequado dos conflitos surgidos no âmbito escolar, especificamente no que tange aos direitos fundamentais da criança e do adolescente, propõe-se a justiça restaurativa como mecanismo indispensável de aperfeiçoamento da jurisdição e do acesso à justiça. Portanto, o presente trabalho defende a criação de espaços para realização de práticas restaurativas nas escolas, no enfrentamento de diferentes tipos de conflitos, de questões disciplinares ou de situações de violência (envolvendo eventuais atos infracionais referidos a delitos de menor 
potencial ofensivo), que possam ser resolvidos por meio de círculos facilitados e organizados por pessoas da própria comunidade escolar.

PALAVRAS-CHAVE: Justiça restaurativa; Educação restaurativa; Violência escolar.

\section{ABSTRACT}

The present article results of the researches developed in the Postgraduate Program in Human Rights and Judicial Provision (interdisciplinary master) and the Interdisciplinary Core Education in Human Rights of the Federal University of Tocantins (UFT), between 2013 and 20I5. Even though we have advanced in the process of democratization of Brazil, without a doubt, we are aware that we are far from a just society and a democratic State that has the interests of the people in the centrality of its actions. For the proper handling of conflicts arising in the context of schools, specifically with regard to fundamental rights of children and adolescents, it is proposed to restorative justice as an indispensable mechanism and improvement of access to justice. Therefore, the present study advocates the creation of spaces for realization of restorative practices in schools in the confrontation of different types of conflicts, disciplinary issues or situations of violence (involving possible acts of minor offences referred to infracionals offensive potential) can be resolved through circles facilitated and organized by people from their own school community.

KEYWORDS: Restorative justice; Restorative education; School violence.

\section{INTRODUÇÃO}

Para o tratamento adequado dos conflitos surgidos no âmbito escolar, especificamente no que tange aos direitos fundamentais da criança e do adolescente, propõe-se a justiça restaurativa como mecanismo indispensável de aperfeiçoamento da jurisdição e do acesso à justiça. Nessa direção, o presente artigo objetiva refletir acerca do arcabouço teórico que sustenta a proposta que se revela como elemento fundante da Educação Restaurativa.

O Brasil vive o paradoxo da necessidade de tornar conhecidos por toda a sociedade os postulados de direitos humanos, como exigência impostergável para instituir-se uma democracia plena no país, quando, ao mesmo tempo, assiste estarrecido graves violações desses direitos, praticados por governos, suas instituições e autoridades. (SILVA, 2003, p. I 5) 
No sistema jurídico brasileiro tem-se um rol de direitos fundamentais estabelecidos na Constituição Federal e procedimentos judiciais específicos para sua proteção, pelos quais os referidos direitos podem ser objeto de demanda.

Uma visão formal do direito ao acesso à justiça não atende à demanda da sociedade atual, porque se busca uma acepção mais ampla do referido direito, não se restringindo apenas ao direito de propor uma ação, mas sim de uma ordem jurídica justa, com a resolução dos conflitos. Sob essa ótica, a via judicial não é o único meio para concretização dos direitos humanos, existem outros instrumentos para solução de conflitos que promovem a pacificação e vêm ao encontro da doutrina de proteção aos direitos humanos, com vista ao respeito è dignidade humana.

Nesse aspecto, o modelo restaurativo se destaca como forma adequada de tratamento e mecanismo consensual de solução de conflitos, e emerge como instrumento de concretização do acesso à justiça. A Resolução $n^{\circ} 12$, de 2002, do Conselho Econômico e Social da Organização das Nações Unidas (ONU), ao dispor sobre os princípios básicos para utilização do referido modelo, conceitua a justiça restaurativa como um "processo através do qual todas as partes envolvidas em um ato que causou ofensa reúnem-se para decidir coletivamente como lidar com as circunstâncias decorrentes desse ato e suas implicações para o futuro".

As práticas restaurativas, nos moldes referenciados pela $\mathrm{ONU}$, têm sido utilizadas no Brasil em procedimentos que versam sobre crianças e adolescentes como forma de responsabilização, restauração e reintegração do adolescente em conflito com a lei. Em razão do sistema estabelecido pelo Estatuto da Criança e do Adolescente, é possível adotar práticas restaurativas desde a etapa pré-processual, com a remissão ministerial até a prolação da sentença, com a possibilidade de aplicação da remissão judicial como forma de suspensão ou exclusão do processo e também por ocasião da execução das medidas socioeducativas.

No Brasil, a introdução da justiça restaurativa no Sistema de Justiça ocorreu em 2005, a partir de projetos desenvolvidos nos Juizados Especiais Criminais do Núcleo Bandeirante, na $3^{a}$ Vara da Infância de Porto Alegre, no Rio Grande do Sul, e na Vara da Infância de São Caetano do Sul, em São Paulo.

\section{JUSTIÇA RESTAURATIVA: NOVOS REFERENCIAIS NA LUTA PELO ACESSO ÀJUSTIÇA}

A Justiça Restaurativa se inspira em modelos tribais de justiça, dentre eles as práticas das comunidades Maori, da Nova Zelândia, as quais foram incorporadas como instrumentos do processo judicial, com prevalência dos interesses coletivos sobre os interesses individuais. $\bigcirc$ modelo neozelandês, consistente nas conferências familiares, com participação do jovem infrator, sua família, da vítima e sua família, é um dos modelos de práticas utilizadas na Justiça Restaurativa. Ademais, temos nas comunidades indígenas 
do Canadá outra importante referência, qual seja, a adoção dos círculos restaurativos, com participação da comunidade e das pessoas envolvidas no conflito. A terceira referência na constituição dos modelos reside na mediação vítima-infrator e, em especial, é a mais usual nas práticas da Justiça Restaurativa, e envolve a participação de um mediador na resolução dos conflitos. Esses são os três modelos restaurativos mais difundidos e adotados pelos sistemas jurídicos internacionais.

Nas sociedades indígenas, donde surge a ideia da Justiça Restaurativa, em lugar de isolar e punir o infrator, a meta da justiça era atingir consenso, envolver família e comunidade na busca de harmonia e reconciliação, promover acordo entre as partes.

No campo teórico, o conceito de Justiça Restaurativa surgiu no final dos anos 1960 e início dos anos 1970, em destaque, com o questionamento dos resultados alcançados pelajustiça retributiva.

Howard Zehr, professor de sociologia jurídica e referência no campo de práticas restaurativas, afirma que o sistema penal considera a culpabilidade do infrator, e a vítima, fundamentalmente, não tem possibilidade de se expressar, uma vez que o crime é cometido contra o Estado. Dessa forma, a Justiça Restaurativa surge como forma para tratar os conflitos, fundada na responsabilidade do autor, concentrando-se nos prejuízos causados e na reconstrução das relações, em sentido contrário ao da justiça retributiva.

marco jurídico de referência na matéria é a Resolução n일 2, de 2002, do Conselho Social e Econômico da ONU, elaborada em face das discussões dos últimos anos sobre os temas de prevenção criminal, respeito às vítimas, e da necessidade de desenvolver instrumentos e princípios para o uso da justiça restaurativa. A referida Resolução define as bases principiológicas para um programa de Justiça Restaurativa, aplicável em qualquer dos sistemas jurídicos dos Estados-Membros.

Por sua vez, o sistema canadense nos traz como marco jurídico de referência paradigmático para o debate da Justiça Restaurativa a interpretação pela Suprema Corte sobre o artigo 7/8.2 do Código Criminal a partir dos casos "Gladue v. the Queen" e "Proulx v. the Queen". Assim, ao discutir o tema, a Suprema Corte trouxe a seguinte definição:

Justiça restaurativa diz respeito à restauração das partes que foram afetadas pela prática de uma ofensa. $\bigcirc$ crime, geralmente, afeta pelo menos três partes: a vítima, a comunidade e o ofensor. A abordagem da justiça restaurativa visa remediar os efeitos adversos do crime, de maneira a enfocar as necessidades de todas as partes envolvidas. Isto é realizado, em parte, através da reabilitação do ofensor, reparação em favor da vítima e da comunidade e promoção de um senso de responsabilidade no ofensor e reconhecimento do dano causado à vítima e à comunidade (SICA, 2006). 
Dado o enfoque da Justiça Restaurativa em bases diversas daquelas da justiça penal atual, duas correntes teóricas se destacam, aquela que defende a possibilidade de substituição do modelo vigente de justiça retributiva pelo modelo restaurativo (minimalistas) e a que coloca a Justiça Restaurativa integrada ao sistema jurídico (maximalista).

\section{OS DESAFIOS MOBILIZADORES NA IMPLANTAÇÃO DA JUSTIÇA RESTAURATIVANO BRASIL}

Atento às demandas da sociedade, o Conselho Nacional de Justiça editou a Resolução n 125, de 29 de novembro de 20 I0, que dispõe sobre a Política Judiciária Nacional de tratamento adequado dos conflitos de interesses no âmbito do Poder Judiciário e prevê, em seu artigo $7^{\circ}$, parágrafo $3^{\circ}$, a existência de programas de Justiça Restaurativa. Vejamos:

Nos termos do art. 73 da Lei $n^{\circ} 9.099 / 95$ e dos arts. 112 e 116 da Lei $n^{\circ}$ $8.069 / 90$, os Núcleos poderão centralizar e estimular programas de mediação penal ou qualquer outro processo restaurativo, desde que respeitados os princípios básicos e processos restaurativos previstos na Resolução n 2002/I2 do Conselho Econômico e Social da Organização das Nações Unidas e a participação do titular da ação penal em todos os atos.

Mais recentemente, o legislador brasileiro, ao regulamentar a execução das medidas socioeducativas - Lei $n^{\circ} 12.594$, de 2012 - estabeleceu, dentre seus princípios, a excepcionalidade da intervenção judicial, privilegiando os meios de autocomposição de conflitos e a prioridade de práticas ou medidas restaurativas, a fim de também atender às necessidades das vítimas.

Dessa forma, o sistema jurídico referente aos direitos da criança e do adolescente já possui em seu arcabouço os instrumentos necessários para implementação do modelo restaurativo, como forma de facilitar o acesso à justiça, efetivando direitos fundamentais, sem necessidade de alterações legislativas.

Dessarte, o arcabouço legislativo do programa de justiça restaurativa, no âmbito da infância e juventude, já se encontra em pleno vigor, necessitando de implementação, o que pode ocorrer tanto na fase pré-processual, quanto na fase processual.

Na fase pré-processual, a aplicação das práticas restaurativas, a exemplo do que ocorreu pioneiramente em São Caetano do Sul - São Paulo -, pode ser implementada nas escolas, buscando-se o enfrentamento da violência escolar por meio da adoção dos princípios da Justiça Restaurativa.

As relações sociais contemporâneas sofreram e sofrem profundas mudanças, as exigências coletivizadas e difusas configuram, como características básicas, a transindividualidade dos anseios e das pretensões sociais e jurídicas. Essas novas nuances 
da sociedade contemporânea, inseridas num contexto de instituições públicas tradicionais e burocráticas, desafiam sobremaneira a criação de estratégias de reorganização, tanto estruturais quanto nos conteúdos de suas respostas, a fim de que sejam oferecidos novos mecanismos de aperfeiçoamento da jurisdição os quais respondam adequadamente às novas exigências impostas pela sociedade. Os níveis de complexidade das atuais relações sociais transformam e fragilizam o desempenho das atribuições estatais, determinando um quadro de crise.

No direito interno, as práticas restaurativas se iniciaram a partir de três experiências distintas, com adoção da corrente maximalista, ou seja, partindo da integração da Justiça Restaurativa ao sistema de justiça, sendo duas delas focadas na resolução de conflitos envolvendo crianças e adolescentes: Juizados Especiais Criminais do Núcleo Bandeirante - nos crimes de menor potencial ofensivo -; $3^{a}$ Vara da Infância de Porto Alegre/RS - na execução das medidas -; e Vara da Infância de São Caetano do Sul/SP nos conflitos estabelecidos no âmbito escolar.

A partir dessas experiências práticas, passa-se a discutir a Justiça Restaurativa como modelo a ser adotado para concretização dos direitos fundamentais de crianças e adolescentes. Nessa perspectiva, ao se ter clara a importância da Justiça Restaurativa no tratamento não adversarial em resolução de conflitos, especialmente no que tange ao proposto neste artigo, na questão relativa à concretização dos direitos humanos e, por consequência, dos direitos fundamentais da criança e do adolescente em conflito com a lei, propõe-se sejam feitas novas perguntas, como por exemplo: Quem sofreu o dano? Quais são as necessidades da vítima? Quem tem a obrigação de consertar o dano causado à vítima? O que levou o autor a cometer a infração?

Portanto, com a preocupação voltada de forma especial à vítima, proporcionam-se algumas transformações no campo dos valores éticos e morais, como por exemplo: a) enquanto na justiça retributiva trabalha-se com o conceito jurídico-normativo de crime, como um ato contra a sociedade representada pelo Estado, sob um aspecto eminentemente unidisciplinar, na justiça restaurativa tem-se o conceito de crime que é realístico, como ato que traumatiza a vítima, causando-lhe danos, proporcionando a possibilidade de ser tratado multidisciplinarmente; b) enquanto na justiça retributiva o primado do Interesse Público é o da sociedade, representada pelo Estado como centro monopolizador da Justiça Criminal, na justiça restaurativa, o primado é o interesse das pessoas envolvidas e a comunidade onde eclodiu a agressão, proporcionando, de forma eficiente e eficaz, uma Justiça Criminal participativa; c) enquanto que, na justiça retributiva, a culpabilidade individual é voltada para o passado, decorrendo um processo de estigmatização do indivíduo infrator, no concernente à justiça restaurativa, a responsabilidade pela restauração ultrapassa a esfera individual, assume dessa maneira, dimensão social, compartilhada coletivamente e voltada para o futuro; por consequência, cria vínculos de solidariedade responsável que terão como expressão social o compromisso pela cultura da paz. 
No que se refere ao procedimento, podem-se destacar os seguintes pontos: a) a justiça retributiva trabalha com o rito solene, dogmático, contencioso, contraditório, e os atores principais são autoridades, profissionais do Direito e o infrator; b) na justiça restaurativa o rito é comunitário, voluntário, colaborativo, e os atores principais são a vítima, o infrator e pessoas da comunidade, com o processo decisório compartilhado com as pessoas envolvidas.

Em relação aos resultados, verifica-se que: a) na justiça retributiva, o foco é na prevenção geral e especial, tendo como centro o infrator, com caráter intimidador e punitivo. A tutela de bens e interesses, com a punição do infrator e proteção da sociedade. As penas geralmente não produzem o resultado esperado. A vítima e o infrator são isolados, desamparados e desintegrados, impondo uma ressocialização secundária, e a construção da paz é baseada na tensão e no medo; b) na justiça restaurativa, a abordagem do crime e suas consequências têm como foco as relações entre as partes, em compromisso conjunto para restaurar. A penalização tem compromisso com o pedido de desculpas, com a restituição, prestação de serviços comunitários e, fundamentalmente, com a reparação do trauma moral e dos prejuízos emocionais, proporcionando a restauração e a inclusão. As penas têm notável eficiência e eficácia, pois se baseiam na proporcionalidade e na razoabilidade das obrigações assumidas no acordo restaurativo. A reintegração da vítima e do autor são prioridades, e a paz é construída na solidariedade com dignidade.

Quanto aos efeitos para as vítimas, constata-se que: a) na justiça retributiva, há pouca consideração, ocupando lugar periférico e alienado no processo, praticamente não participa nem compreende o que está se passando. A assistência psicológica, social, econômica ou até mesmo jurídica é deficiente e ineficaz, desencadeando um processo de profunda frustração e ressentimento com o sistema, tanto pela vítima, quanto por seus familiares e comunidade; b) na justiça restaurativa, a vítima ocupa o centro do processo, desempenha papel com voz ativa, participa e até mesmo tem controle sobre o que se passa. Recebe assistência, afeto, restituição de perdas materiais e reparação emocional; dessa maneira há a construção de confiabilidade no sistema, criação e fortalecimento nos laços familiares e comunitários. Assim, os ganhos são positivos e há o atendimento das necessidades individuais e coletivas da vítima e comunidade.

E, por fim, no tocante aos efeitos para o infrator, observa-se que: a) na justiça retributiva, é considerado em suas faltas e má-formação. Participa por meio de representante, com rara oportunidade de se expressar. É inibido a se aproximar e a dialogar com a vítima, desinformado e alienado quanto aos atos processuais, não é responsabilizado, e sim punido, e suas necessidades geralmente não são consideradas; b) na justiça restaurativa, o infrator é visto na forma de seu potencial de responsabilizarse pelos danos e consequências do delito, participa ativa e diretamente, é estimulado a interagir com a vítima e com a comunidade, criando a oportunidade de se desculpar ao sensibilizar-se com o trauma da vítima, é informado sobre os atos do processo 
restaurativo, contribui para a decisão e é inteirado das consequências do fato para a vítima e comunidade, envolvendo-se de forma importante e significativa com o processo e criando compromisso de ações não infratoras.

\section{OAMBIENTE ESCOLARE AJUSTIÇA RESTAURATIVA}

Parte dos conflitos anteriormente mencionados, envolvendo infratores de um lado e vítimas de outro, ocorrem no ambiente escolar e acabam desaguando no sistema de justiça, com a judicialização da violência escolar. A violência no ambiente escolar pode ter origem na desigualdade social, injustiça social e até mesmo reprodução da violência vivenciada no âmbito familiar.

Eduardo Resende Melo (2005, p. 70) afirma que:

a escola, de fato, é o grande espaço de detecção de situações de violência e de denegação de direito a criança e adolescentes. É nela também que se apresenta com maior evidência as conseqüências do processo de exclusão social a que é reduzida boa parte da população. É dela, ademais, que se espera a transformação desse realidade, sem Ihe dar suporte necessário. Situações de violência são comuns e constantes na escola e elas, sozinhas, não são capazes de dar conta de problemas que as transcendem. Ao mesmo tempo, é essa mesma escola chamada ao desafio de estimular um juízo crítico e formar crianças e adolescentes para a cidadania. De fato, à escola tende todo processo socioeducativo. É para lá que se busca o retorno do adolescente em conflito com a lei. Ainda que o ato infracional não tenha sido cometido no entorno daquela escola, sendo o adolescente oriundo de tal escola, será no contexto dela que haverá de seguir sua vida e é nela que haverá de encontrar o espaço de acolhimento e de reflexão sobre as razões e conseqüências de seu ato, reavaliando sua conduta e seu modo de ação no mundo. Tomar então a escola ao mesmo tempo como ponto de partida e de chegada desse processo de inclusão e de emancipação simboliza ao adolescente, de modo mais concreto, o sentido da atuação da justiça na resolução de conflitos.

Importa dizer que a violência na escola implica, muitas vezes, evasão escolar e falta de motivação dos professores. Estabelecer a cultura da paz nas escolas, como forma de tratamento dos conflitos e enfrentamento da violência existentes no âmbito escolar, surge como meio consensual de resolução de conflitos, com a participação da comunidade, da família, dos educadores e dos próprios alunos e também forma de prevenção desses conflitos.

Nos espaços escolares, é pioneira no Brasil a construção do programa "Justiça Restaurativa e Comunitária em São Caetano do Sul: parceria pela cidadania", em 2005, com a mobilização do Judiciário paulista com a Secretaria de Estado da Educação, o Conselho Municipal de Direitos da Criança e Adolescente, o Conselho Tutelar, o 
Conselho Municipal de Segurança, o Cartório da Infância e da Juventude, dentre outros parceiros.

A partir de então, práticas restaurativas foram adotadas em diversas regiões do país, capitaneadas pelo sistema de justiça, como forma de prevenção e tratamento não adversarial de conflitos, com empoderamento da comunidade escolar.

Segundo aponta pesquisa realizada, em 2010, pela ONG Plan Brasil, aproximadamente $70 \%$ dos estudantes das escolas brasileiras já presenciaram algum tipo de agressão entre os colegas; $30 \%$ deste total afirmam ter sido vítimas dessas agressões. Outra importante pesquisa divulgada, em 2013, pelo Sindicato dos Professores do Ensino Oficial de São Paulo (APEOESP) revela que 44\% dos professores da rede estadual paulista sofreram algum tipo de violência na escola. A agressão verbal atinge 39\% dos professores, seguida do assédio moral ( 10\%), bullying (6\%) e, por fim, agressão física (5\%). Segundo dados da referida pesquisa, quatro entre dez professores já foram vítimas de algum tipo de violência na unidade escolar.

No estado do Tocantins, alguns dados revelam a necessidade de atenção especial ao problema da violência escolar. Por exemplo, extrai-se dos dados estatísticos do Tribunal de Justiça do Estado do Tocantins (TJTO) que, em 20 I3, foram autuados I 46 Boletins de Ocorrência Circunstanciada no Juizado da Infância e Juventude da Comarca de Araguaína, referentes a atos infracionais cometidos por adolescentes. Ainda que o quantitativo em números absolutos, aparentemente, não cause tanta apreensão devido ao universo populacional; sem dúvida, a nossa atitude tende a mudar quando nos debruçamos nos detalhes dos respectivos processos.

Nesse contexto, a Resolução n 9, de 5 de julho de 2012, do Tribunal de Justiça, dispõe sobre a criação do Núcleo Permanente de Métodos Consensuais de Solução de Conflitos no âmbito do Poder Judiciário do Estado do Tocantins; sem dúvida, significa um importante instrumento para avançar na prestação jurisdicional no Estado.

Nesse contexto, evidencia-se a preocupação com a efetividade e qualidade da prestação jurisdicional, fundamentalmente no que tange à concretização dos direitos humanos, como elemento essencial de ordem justa e solidária.

Assim, a implementação da justiça restaurativa nas escolas objetiva contribuir para a transformação de escolas e comunidades que vivenciam situações de conflito e violência, em espaços de diálogo e resolução pacífica de conflitos. A criação de espaços de realização de círculos restaurativos nas escolas para o enfrentamento de diferentes tipos de conflitos, questões de disciplina ou situações de violência (envolvendo eventuais atos infracionais referidos a delitos de menor potencial ofensivo) apresenta-se como uma proposta que admite ter nas pessoas da própria comunidade escolar sujeitos facilitadores e organizadores.

Os processos circulares têm suas origens nas comunidades aborígenes do Canadá e passaram a ser utilizados em diversos países que implantaram a justiça restaurativa. No Canadá, o juiz Barry Stuart os denominou de círculos de construção da paz.

Os encontros que antecedem o círculo são chamados de pré-círculos e se destinam 
a averiguar a possibilidade de encaminhamento do caso, obter o consentimento das partes envolvidas e repassar todo o procedimento para ofensor, vítima e demais participantes, a fim de que estejam plenamente cientes do desenrolar de todo o processo restaurativo. Nos círculos há participação da vítima, do ofensor, familiares de ambos, pessoas da comunidade, além de profissionais do judiciário, sem obrigatoriedade de sua participação.

Para Amstutz (20 I 2), são elementos-chave dos processos circulares o respeito às crenças de cada membro da comunidade, a vontade de todos se relacionarem de forma positiva, os valores que cada um crê necessário para manter um relacionamento de forma positiva, os facilitadores e o bastão da fala.

Nesse modelo de justiça restaurativa, as reuniões ocorrem com as pessoas acomodadas num círculo, as quais têm a oportunidade de se expressar quando estão em poder do "bastão da fala", o qual deve passar de mão em mão, na ordem em que as pessoas se encontram sentadas. Os facilitadores, também denominados "guardiães do círculo", dirigem as reuniões, orientando os participantes, conforme explica Brancher $(20||)$ :

A principal característica desses encontros está em que a palavra é colocada à disposição dos presentes, de forma sequencial e rotativa. Coloca-se em circulação entre os presentes um objeto ("bastão falador"), que passa de mão em mãos, e cuja posse autoriza o portador a fazer uso da palavra - único momento em que cada pessoa poderá se manifestar, exceção feita apenas ao coordenador do encontro. A cada rodada, os participantes são convidados a manifestarem-se a respeito de um tema diferente. É comum essas etapas aparecerem relacionadas aos quadrantes do círculo, por sua vez indicando etapas rituais de um processo simbólico de transformaç̧ão. (BRANCHER, 20 I I , p. 9)

Durante a realização do círculo o facilitador é um participante, e o objeto da palavra é que regulamenta o diálogo, ou seja, quem estiver com o objeto escolhido é quem poderá falar. A posse do objeto da fala possibilita que a pessoa expresse seus sentimentos e suas vontades, mas não a obriga a falar. De outro modo, o bastão da fala impõe a escuta qualificada, já que somente a pessoa que o detém poderá falar, todas as outras estarão aptas a ouvir atenta e respeitosamente o que ela falar. A intervenção do facilitador, quando não estiver com o objeto, é permitida apenas para manter a ordem no processo circular.

Amstutz (20 I 2) discorre sobre o bastão de fala, explicando sua função:

É um objeto focal aceito e usado pelo grupo. Em geral trata-se de algo que tenha um significado especial para o grupo. Proporciona oportunidade de escutar e refletir antes de falar, já que todos devem esperar a sua vez para se manifestarem no momento em que recebem o bastão de fala. Assim, os participantes tendem a prestar mais atenção ao que as pessoas estão dizendo em vez de preparar uma 
resposta imediata. Evitar altercação entre duas pessoas, já que todos devem esperar sua vez para falar. Estimula a responsabilidade partilhada durante a discussão. Reforça a igualdade no círculo, já que proporciona igual oportunidade a todos os participantes.

Abre maior espaço para aqueles que em geral ficam em silêncio, já que não precisam mais competir por espaço com aqueles que são mais extrovertidos. (AMSTUTZ, 2012, p. 78)

As diretrizes para o uso do referido objeto, segundo Amstutz (20 I 2), devem prever o uso da palavra apenas pela pessoa que estiver portando o objeto, a qual deverá se manifestar sempre de forma respeitosa para com os demais integrantes do círculo, além de usar a palavra parcimoniosamente, oportunizando assim que todos se manifestem. Nos círculos, a pessoa também pode deixar de falar, se assim o desejar, devendo sempre respeitar a confidencialidade do que for partilhado durante sua realização.

A escolha de uma peça de centro pelo facilitador, a ser colocada no espaço aberto pelo círculo de cadeiras, deve considerar a cultura dos participantes. Trata-se de uma peça que deverá evocar hospitalidade, conforto, familiaridade. Durante a realização do círculo muitas vezes essa peça de centro será um amparo para os participantes, um foco que lhes possibilitará falar e ouvir sinceramente. Rotineiramente se usa um tecido como base, com peças diversas dispostas sobre ele, que representem o grupo e os valores de um círculo.

A estrutura dos círculos segue a seguinte dinâmica: escolha prévia do centro e do objeto da palavra, pelo facilitador; realização da cerimônia de abertura; apresentação/check in; escolha dos valores a serem respeitados; fixação das diretrizes; contação de histórias; abordagem dos problemas; geração de acordos; consenso; check out; cerimônia de encerramento.

A cerimônia de abertura é utilizada para marcar o início de algo importante, usada como um convite para adentrar no espaço do círculo e se desligar do que acontece fora dele, conectando-se com as demais pessoas presentes. Nesse espaço, as pessoas devem ser verdadeiras e estarem centradas no que ocorre no círculo, sem distrações. A leitura de textos de meditação ou poemas, músicas e dinâmicas em grupo podem ser utilizadas como cerimônias de abertura.

A apresentação ou check in deve ser feita em seguida, com todos os participantes se apresentando, com o uso do bastão da fala. Na apresentação, pode ser feita uma pergunta a ser respondida por todos os participantes do círculo, a fim de que se conheçam melhor e estabeleçam vínculo e empatia, alcançando a integração de todos. Exemplo de perguntas que podem ser feitas no check in: Como você está se sentindo hoje? Que lembrança feliz você tem da sua infância?

Em seguida, os participantes devem discutir os valores a serem respeitados no círculo, bem como fixar as diretrizes a serem seguidas durante sua realização. Os valores e diretrizes devem ser objeto de consenso entre os participantes, expressando a forma como cada um se sentirá seguro ao expor sentimentos e emoções dentro do círculo. 
Tais valores devem ser escritos e deixados no centro do círculo, garantindo que todos se lembrem de como se comportar durante sua realização. Respeito, confidencialidade, ética, sinceridade, humildade, compreensão são valores comumente colocados como essenciais para a participação efetiva no círculo.

Na contação de histórias, os participantes, por meio de perguntas norteadoras a serem feitas pelo facilitador, passam a partilhar suas vidas, criando empatia e possibilitando a compreensão do agir de cada um.

Após a contação de histórias, passa-se a explorar o problema que é o objetivo do círculo. Os facilitadores devem fazer uma pergunta pertinente ao assunto, e então passar o objeto da palavra. As perguntas devem ser formuladas para facilitar a discussão e possibilitar o foco nos sentimentos, e não nos fatos ocorridos, evitando-se ataques entre os participantes.

Nesse ponto, é importante a observância dos valores e diretrizes fixadas pelo grupo, podendo haver várias rodadas de perguntas, a fim de que se alcance a reflexão sobre as atitudes que ocasionaram o problema e as soluções para seu deslinde. Não se trata aqui de estabelecer culpados, mas de alcançar a responsabilização, o reconhecimento do mal causado, e a busca da melhor alternativa para reparação dos danos. Qualquer acordo alcançado por meio do círculo deve ser obtido de forma consensual, sem imposições. $\bigcirc$ facilitador deve buscar que os próprios participantes apresentem soluções, sem sua interferência com sugestões.

Na rodada de check out, o objeto da palavra será repassado, convidando os participantes a compartilhar seus sentimentos em relação ao círculo. $\bigcirc$ participante pode resumir, numa palavra, como se sente após a realização do círculo.

A cerimônia de fechamento é importante para preparar as pessoas para o retorno às suas atividades comuns do dia a dia, reconhecer o esforço da participação de cada um, além de expressar a interconexão do grupo. Assim como na cerimônia de abertura, podem ser feitas leituras ou meditação, ouvir uma música, ou fazer uma dinâmica de grupo.

Após a realização do círculo, e ocorrendo a elaboração de um acordo, são feitos pós-círculos, novamente com a participação de todos aqueles que estiveram presentes no círculo, a fim de averiguar se o acordo foi cumprido e qual o resultado para todos eles.

Para atuar como facilitador nos círculos não há exigência de escolaridade, ou de outra espécie; trata-se de função que pode ser atribuída a qualquer pessoa da comunidade, devidamente capacitada, conforme se pode inferir dos programas de práticas restaurativas em andamento no país, atentando-se para a necessidade de contínua capacitação dos facilitadores, a fim de garantir uma atuação de maneira justa e imparcial. 


\section{CONSIDERAÇÕES FINAIS}

Nos mais diversos tipos de discurso, muito comum é se ouvir apontar a Educação como saída para resolução de grande parte dos problemas sociais, um tipo de panaceia. Dessa maneira, o cuidado para que não se promova uma falsa promessa exige maior rigor teórico na formulação de políticas públicas compreendendo-as num contexto de disputa de projetos de sociedade e, em especial, resistindo e buscando derrotar as propostas de inspiração neoliberal que, em última instância, é a negação da justiça.

Se quando o direito à segurança, à incolumidade, está em jogo, e se recebe do Estado uma resposta de cidadania, de reconhecimento, de respeito, há assim uma criação direta de mecanismo de construção de cultura em diretos humanos. Dessa forma, os direitos humanos só podem ser verdadeiramente concretizados numa sociedade em que há cultura de respeito a direitos. No cotidiano da sociedade, é preciso que haja a valoração de tais direitos, como uma baliza social determinante do comportamento. Portanto, se não é por meio da Educação e da Cultura que os direitos humanos serão concretizados, certamente, sem eles e apenas por meio de coerção estatal, é que tal concretização não acontecerá.

A sociedade ocidental vive um momento de crise na qual o enfrentamento aos postulados propugnados pelo neoliberalismo (TORRES SANTOMÉ, 2003) adquire centralidade, e, em especial, o desafio do mundo contemporâneo é conciliar o individualismo com os interesses sociais, coletivos. Numa sociedade egoística e obcecada pelo consumo, preciso é construir elos que unam as pessoas enquanto seres humanos, sujeitos de direitos universais (BAUMAN, 200 I , p.74).

No Brasil, alguns dos aspectos dessa crise podem ser compreendidos como a crescente distância entre a legislação e a realidade social, a dificuldade de efetivação e concretização dos direitos fundamentais pelas decisões judiciais e na promoção do direito ao acesso à justiça, para além do aspecto formal perante os órgãos judiciários, como fundamentalmente o acesso a uma ordem jurídica justa. Portanto, surge a necessidade de interpenetração entre as esferas pública e privada, pois essa é uma das características importantes do direito de solidariedade, caracterizado essencialmente por seu caráter transindividual, refletindo, dessa maneira, na necessidade de novas práticas administrativas, jurisdicionais, legislativas e políticas.

A proteção efetiva aos direitos humanos não se faz apenas por meio da prestação jurisdicional; afinal, a sociedade complexa reclama por mais mecanismos que levem ao respeito da dignidade do homem. Sobre esse aspecto, Rodolfo de Camargo Mancuso nos leva a refletir:

A experiência tem mostrado que não adianta focar apenas a 'produção de respostas jurisdicionais, sem atentar para o input, ou seja, para a entrada massiva e crescente de novos processos, os quais, em sua grande maioria, poderiam e deveriam ser endereçadas a outros órgãos e instâncias, inclusive os 
parajurisdicionais, capazes de recepcioná-los e resolvê-los em modo justo e tempestivo. Aí, sim, se estaria a lidar com a causa, ao invés, de apenas tentar combater as consequências, como até hoje, basicamente, se tem feito. (MANCUSO, 201 I, p. I86)

Nessa esteira, promover ampla e irrestrita educação em direitos humanos é elemento indispensável para que a concretização e a efetivação dos direitos fundamentais consagrados possam verdadeiramente acontecer. Portanto, a adoção de práticas restaurativas no ambiente escolar é, acima de tudo, um ato político-pedagógico que colabora na viabilização da construção de uma Cultura da Paz.

\section{REFERÊNCIAS}

ABRAMOWAY, Miriam.Violência nas Escolas. Brasília: UNESCO, 2002.

ANDERSON, Perry. Balanço do neoliberalismo. In: SADER, E.; GENTILI, P. (Orgs.) Pós-neoliberalismo. As políticas sociais e o Estado democrático. Rio de Janeiro: Paz e Terra, 1995.

AMSTUTZ, Lorraine Stutzman; MULLET, Judy H. Disciplina restaurativa para escolas: responsabilidade e ambientes de cuidado mútuo. Trad. Tônia Van Acker. São Paulo: Palas Athena, 2012.

BARONI, Mariana Custódio de Souza. Justiça restaurativa na escola: trabalhando as relações sociomorais. Presidente Prudente: Universidade Estadual Paulista, 20 I I Dissertação (Mestrado) - Universidade Estadual Paulista, Presidente Prudente, 20 I l. Disponível em: <http://www.athena.biblioteca.unesp.br/exlibris/bd/bpp /33004 I 29044P6/20 I I/baroni_mcs_me_prud.pdf > Acesso em 30 jul. 20 I 4.

BAUMAN, Zygmund. Modernidade Líquida, Rio de Janeiro: Jorge Zahar Editor, 2001 .

BRANCHER, L.; AGUINSKY, B. Projeto Justiça para o Século 21. Disponível em: <http://www.justica21.org.br/j2I/webcontrol/upl/bib_24l.doc $>$

BRANCHER, Leoberto; KOZEN, Afonso; AGUINSKY, Beatriz. Justiça Restaurativa. Brasília, CEAG, 20l I. Disponível em: <http://www8.tjmg.jus.br/jij/apostila_ceag/MODULO_IX.pdf>. Acesso em 20 set. 2014. 
BRASIL. CONSELHO NACIONAL DE JUSTIÇA. Resolução n 125, de 29 de novembro de 2010. Dispõe sobre a Política Judiciária Nacional de tratamento adequado dos conflitos de interesses no âmbito do Poder Judiciário. Disponível em: $<$ http://www.cnj.jus.br/busca-atos-adm?documento=2579> Acesso em nov. 2013.

BRASIL. Lei I2.594/20 I2. Institui o Sistema Nacional de Atendimento Socioeducativo. Disponível em: < http://www.planalto.gov.br/ccivil_03/_ato20lI20l4/20 I2/lei/l 2594.htm> Acesso em ago. 20 I 4.

BRASIL. Resolução I2/2002 da ONU, de 24 de julho de 2002. Princípios Básicos Para Utilização de Programas de Justiça Restaurativa em Matéria Criminal. Justiça para o Século 21. [s.l.], p. 06, 24 jul. 2002 . Disponível em: <http://justica2l.org.br/j2I.php?id=366\&pg=0\#.U3UV2IFdXXA>. Acesso em 21 set. 2014 .

CHRISPINO, Alvaro; CHRISPINO, Raquel S. P. A judicialização das relações escolares e a responsabilidade civil dos educadores. In: Ensaio: avaliação de políticas públicas. Educ., Rio de Janeiro, v. 16, n. 58, p. 9-30, jan./mar. 2008. Disponível em: <http://www.scielo.br/pdf/ensaio/v l 6n58/a02v l 658.pdf>. Acesso em 28 jul. 20 I 4.

COMPARATO, Fabio Konder. Afirmação histórica dos direitos humanos. São Paulo: Saraiva, 2010.

DISKIN, Lia. Cultura de paz: redes de convivência. Disponível em: <http://wwwl.sp.senac.br/hotsites/gd4/culturadepaz/arqs/cartilha.pdf>. Acesso em 28 jul. 2014.

FERREIRA, Francisco Amado. Justiça Restaurativa: Natureza. Finalidades e Instrumentos. Coimbra: Coimbra, 2006.

HARVEY, D. A condição pós-moderna. São Paulo: Loyola, 1992.

LUCAS, Doglas Cesar e SPENGLER, Fabiana Marion (orgs.). Justiça Restaurativa e Mediação. ljuí: Unijuí, 20। I.

MANCUSO, Rodolfo de Camargo. Acesso à justiça. São Paulo: RT, 201 I .

McCOLD, P. e WACHTEL, T. Em Busca de um Paradigma: Uma Teoria de Justiça Restaurativa. Trabalho apresentado no XIII Congresso Mundial de Criminologia, I0- I 5 Agosto de 2003, Rio de Janeiro. Disponível em: <http://irp.org/library/paradigm_port.html>. Acesso em I 0 fev. 2013. 
MELO, Eduardo Rezende. Justiça restaurativa e seus desafios histórico-culturais. Um ensaio crítico sobre os fundamentos ético-filosóficos da justiça restaurativa em contraposição à justiça retributiva. In: SLAKMON, Catherine, (org.) et al. Justiça Restaurativa: coletânea de artigos. Brasília, DF: Ministério da Justiça e PNUD, 2005.

MELO, Eduardo R.; EDNIR, Madza; YAZBEK, Vania C. Justiça Restaurativa e Comunitária em São Caetano do Sul: Aprendendo com os conflitos a respeitar direitos e promover cidadania. Secretaria Especial dos Direitos Humanos da Presidência da República. Rio de Janeiro: CECIP, 2008.

MENEZES, Lívia. Violência escolar: o professor sob ameaça. Folha Dirigida, out. 20 I 3. Disponível em: < www.apeoesp.org.br/d/sistema/publicacoes/57//arquivo/pagina16.pdf $>$ Acesso em abr. 20 | 4.

PELIZZOLI, Marcelo (Org.). Cultura de Paz: Restauração e Direitos. Recife: Universitária UFPE, 2010.

POLATO, Amanda. Cerca de $70 \%$ dos estudantes já presenciaram violência na escola, afirma pesquisa inédita, 20l0. Disponível em: < http://noticias.r7.com/educacao/noticias/cerca-de-70-dos-estudantes-japresenciaram-violencia-na-escola-20 l004|4.html> Acesso em fev. 20 l 4.

SANTANA, Clóvis da Silva. Justiça Restaurativa na Escola: reflexos sobre a prevenção da violência e a indisciplina grave e na promoção da cultura de paz. Universidade Estadual Paulista, Faculdade de Ciências e Tecnologia. Presidente Prudente. Dissertação de Mestrado.20। I. Disponível e m: < http:// www4.fct.unesp.br/pos/educacao/teses/20ll/diss_clovis.pdf>. Acesso em 2 ago. 2014.

SARLET, Ingo Wolfgang. A eficácia dos direitos fundamentais. $6^{\mathrm{a}}$ ed. Porto Alegre: Livraria do Advogado, 2006.

SICA, Leonardo. Bases para o modelo Brasileiro de Justiça restaurativa in Novas direções na governança da Justiça e da Segurança. (C. Slakmon, M. R. Machado, \& P. C. Bottini, Eds.) Brasília, Distrito Federal: Ministério da Justiça, 2006.

SILVA, Suamy Santana da. Teoria e prática da educação em Direitos Humanos nas Instituições policiais brasileiras. Porto Alegre: Edições CAPEC, 2003. 
TOCANTINS. Tribunal de Justiça do Estado do Tocantins. Resolução n 9, de 05 de julho de 2012. Dispõe sobre a criação do Núcleo Permanente de Métodos Consensuais de Solução de Conflitos no âmbito do Poder Judiciário do Estado do Tocantins. Disponível em: <http://wwa.tjto.jus.br/elegis/Home/lmprimir/394> Acesso em nov. 2013.

TORRES SANTOMÉ, Jurgo. A educação em tempos de neoliberalismo. Porto Alegre: Artmed, 2003.

VASCONCELOS, Carlos Eduardo de. Mediação de conflitos e práticas restaurativas. São Paulo: Método, 2008.

VEZZULLA, Juan Carlos. A Mediação de Conflitos com Adolescentes Autores de Ato Infracional. Florianópolis: Habitus, 2006

ZEHR, Howard. Justiça Restaurativa. Tradução de Tônia Van Acker. São Paulo: Palas Athena, 2012.

ZEHR, Howard. Trocando as lentes - um novo foco sobre o crime e a justiça. São Paulo: Palas Athena, 2008.

Recebido em: 18/05/2016 Aprovado em: 01/06/2016 